\title{
Cinética de fermentação ruminal das silagens de três híbridos de milho comerciais em diferentes estádios de maturação
}

\author{
[Ruminal fermentation kinetics of corn silages from three commercial hybrids at \\ different maturation stages]
F.P. Pôssas ${ }^{1}$, L.C. Gonçalves ${ }^{1}$, L.G.R. Pereira ${ }^{2}$, F.S. Machado ${ }^{2}$, D.G. Jayme ${ }^{1}$, J.A.S. Rodrigues ${ }^{3}$, N.M. Rodriguez, $z^{1}$ T.R. Tomich ${ }^{2}$ \\ ${ }^{1}$ Escola de Veterinária - Universidade Federal de Minas Gerais - UFMG - Belo Horizonte, MG \\ ${ }^{2}$ Embrapa Gado de Leite - CNPGL - Juiz de Fora, MG \\ ${ }^{3}$ Embrapa Milho e Sorgo - CNPMS - Sete Lagoas, MG
}

\begin{abstract}
RESUMO
Foi avaliada a cinética de fermentação ruminal in vitro de três híbridos comerciais de milho (BRS 1035, BRS 1031 e BRS 1001) colhidos em três estádios de maturidade (pastoso, farináceo e farináceo-duro). Após 96 horas de fermentação, não houve diferença na PCG entre as silagens dos híbridos colhidos nos diferentes estádios de maturidade $(\mathrm{P}>0,05)$. O potencial máximo de produção de gases das silagens de todos os híbridos reduziu com o avançar da maturidade da planta, sendo a variação encontrada de 259,3 a $280,0 \mathrm{~mL} / \mathrm{g}$ de matéria seca (MS). Os valores de tempo de colonização variaram de 0h06min a $1 \mathrm{~h} 54 \mathrm{~min}$. Para as silagens dos híbridos BRS 1035 e BRS 1001, houve aumento no tempo de colonização com o avançar da maturidade da planta. Para as silagens do híbrido BRS 1031, houve aumento dos valores de tempo de colonização quando a planta avançou do estádio pastoso para farináceo, e reduziu quando a maturidade alcançou o estádio farináceo-duro. A taxa fracional de produção de gases " $\mu$ " variou entre $0,03 \mathrm{~mL} / \mathrm{h}$ a $0,05 \mathrm{~mL} / \mathrm{h}$. Com o avançar da maturidade fisiológica, as silagens dos híbridos BRS 1035 e BRS 1001 apresentaram aumento nos valores de $\mu$; já para as silagens do híbrido BRS 1031, os valores de $\mu$ aumentaram quando o estádio de maturidade avançou de pastoso para farináceo, e reduziu para farináceo-duro. Os valores das degradabildades efetivas foram superiores para as silagens dos diferentes híbridos colhidas no estádio pastoso. As degradabilidades da MS com o tempo de fermentação de 96 horas variaram de 70,1 a 76,4\%. A silagem do híbrido BRS 1035 apresentou melhor valor nutricional quando colhida no estádio pastoso de maturidade. Já a silagem do híbrido BRS 1031 apresentou valor nutricional superior no estádio farináceo, enquanto a silagem do híbrido BRS 1001 apresentou melhor valor nutricional no estádio farináceo-duro.
\end{abstract}

Palavras-chave: produção de gases, degradabilidade, estádio de maturidade, silagem de milho

\begin{abstract}
The in vitro ruminal fermentation kinetics of three commercial corn hybrids (BRS 1035, BRS 1031 and BRS 1001) harvested at three maturity stages (soft dough, floury and hard-floury) were evaluated. After 96 hours of fermentation there was no change in the cumulative gas production (GPC) among silages harvested for all hybrids $(P>0.05)$. The silages maximal degradation potential for all hybrids decreased with advanced maturity stages, and ranged from 259.32 to $279.96 \mathrm{~mL} / \mathrm{g}$ of dry matter. The lag values ranged from Oh 06min to $1 \mathrm{~h} 54 \mathrm{~min}$. For silages from the BRS 1035 and BRS 1001 hybrids, there was an increase in lag with advancing plant maturity. For silage from the BRS 1031 hybrid, the lag values increase when the plant moved of soft dough stage to floury, and was reduced to hard-floury stage. The fractional rate of gas production $\mu$ ranged from $0.0292 \mathrm{~mL} / \mathrm{h}$ to $0.0447 \mathrm{~mL} / \mathrm{h}$. With advancing physiological maturity stages, the hybrids BRS 1035 and BRS 1001 showed an increase in the $\mu$ values, since for silage from the BRS 1031 hybrid, the value of $\mu$ increased when the maturity stage progressed
\end{abstract}

Recebido em 25 de julho de 2013

Aceito em 3 de outubro de 2014

E-mail: fpimont@gmail.com 
from soft dough to floury, and reduced to hard-floury. The values of effective degradability were higher for silages from different hybrids harvested at soft dough. The dry matter degradability (DMD) in the fermentation time of 96 hours ranged from 70.14 to $76.40 \%$. The silage from the BRS 1035 hybrid showed better nutritional value when harvested in the soft dough stage of maturity. The silage from the BRS 1031 hybrid showed highest nutritional value at the floury stage, while the silage from the BRS 1001 hybrid showed better nutritional value in the hard-floury stage.

Keywords: gas production, degradability, maturity stages, corn silage

\section{INTRODUÇÃO}

Nos sistemas de produção de ruminantes, para que se consiga boa produtividade dos animais durante todo o ano, precisa-se pensar em alternativas para conservação da forragem produzida durante a estação chuvosa, de forma que possa ser utilizada durante o período de escassez de chuva.

A ensilagem tem sido o método mais utilizado para conservação de forragens, pois é menos dependente das variações climáticas, é rápida $\mathrm{e}$ não requer maquinário especializado. $\mathrm{O}$ milho tem sido a espécie forrageira mais utilizada para esse fim por apresentar bom valor nutricional, alto potencial produtivo de matéria seca por hectare, baixo custo de produção, facilidade de colheita e de ensilagem e pelo grande número de cultivares adaptados a diferentes situações.

O valor nutricional da planta original reflete muito no valor nutricional do material após a ensilagem, desde que todas as etapas desse processo sejam realizadas conforme as recomendações técnicas. Porém, com o avançar da idade da planta, ocorre aumento da produção de matéria seca juntamente com uma maior participação de espigas na massa produzida, de forma que o valor nutricional da planta é determinado tanto pelo percentual de participação de cada uma das frações da planta (espiga, caule e folha) como pela digestibilidade de cada uma dessas frações.

A técnica in vitro semiautomática de produção de gases faz a mensuração dos gases produzidos a partir da fermentação do substrato em meio de cultura acrescido de inóculo microbiano em meio anaeróbico. Com isso, consegue-se descrever a cinética de fermentação, a taxa e a extensão da degradação das forrageiras, com a vantagem de se conseguir avaliar um grande número de amostras com baixo custo e alta repetibilidade.
Objetivou-se com este trabalho avaliar a cinética de fermentação das silagens de três híbridos de milho comerciais (BRS 1035, BRS 1031 e BRS 1001) colhidos em três idades, pela técnica in vitro semiautomática de produção de gases.

\section{MATERIAL E MÉTODOS}

Três híbridos de milho comerciais (BRS 1035, BRS 1031 e BRS 1001) foram plantados no campo experimental do Centro Nacional de Pesquisa de Milho e Sorgo (CNPMS) da EMBRAPA, localizado no município de Sete Lagoas, Minas Gerais, no ano agrícola 2006/2007, sendo cortados em três diferentes estádios de maturação dos grãos: pastoso, farináceo e farináceo-duro, correspondendo a 87 , 94 e 101 dias após plantio, respectivamente. Esses híbridos são originados do programa de melhoramento genético da Embrapa Milho e Sorgo. Os híbridos foram cortados rente ao solo e picados com auxílio de ensiladeira, e imediatamente ensilados em tambores metálicos com capacidade para 200 litros cada, revestidos internamente com sacos plásticos. O material foi compactado sob pisoteio e os tambores foram vedados com auxílio de travas nas tampas. Posteriormente, os tambores foram abertos e amostras foram retiradas para a execução do ensaio. A composição química das silagens é apresentada na Tabela 1. O ensaio de produção de gases foi realizado nas dependências da Embrapa Gado de Leite, em Juiz de Fora, Minas Gerais, utilizando-se a técnica semiautomática de produção de gases, conforme a metodologia proposta por Maurício et al. (2003).

As amostras das silagens foram secas em estufa de ventilação forçada a $55^{\circ} \mathrm{C}$, moídas em moinho tipo "Willey" com peneiras de $1 \mathrm{~mm}$ e armazenadas em recipientes plásticos. As amostras de cada tratamento foram acondicionadas em frascos $(50 \mathrm{~mL})$. Visando à manutenção de fermentações anaeróbicas, em todos os frascos foi injetado $\mathrm{CO}_{2}$ anteriormente à 
adição do substrato. Foi adicionado a cada frasco $0,3125 \mathrm{~g}$ de substrato, conforme recomendações de Belvink e Spoelstra (1992), utilizado-se três frascos por tratamento (três réplicas para cada uma das amostras). Foram adicionados $28 \mathrm{~mL}$ de meio de cultura em cada frasco (Menke et al., 1979).

Tabela 1. Valores de matéria seca (MS), proteína bruta (PB), fibra em detergente neutro (FDN), fibra em detergente ácido (FDA), hemiceluloses (HEM), celulose (CEL) e lignina (Lig) em porcentagem da MS das silagens de três híbridos de milho colhidos nos pontos pastoso, farináceo e farináceo-duro

\begin{tabular}{lccccccc}
\hline \multirow{2}{*}{ Híbridos } & \multicolumn{7}{c}{ Composição química } \\
\cline { 2 - 7 } & MS & PB & FDN & FDA & HEM & CEL & Lig \\
\hline BRS 1035 & 23,96 & 7,03 & 61,68 & 34,02 & 27,66 & 29,58 & 4,39 \\
Pastoso & 30,45 & 5,18 & 59,81 & 33,16 & 26,65 & 28,87 & 4,44 \\
Farináceo & 35,08 & 5,97 & 64,69 & 34,74 & 29,95 & 29,91 & 4,69 \\
Farináceo-duro & & & & & & & \\
\hline BRS 1031 & 23,73 & 8,06 & 54,86 & 31,81 & 23,05 & 27,68 & 4,01 \\
Pastoso & 30,91 & 6,38 & 51,96 & 27,45 & 24,51 & 23,80 & 3,27 \\
Farináceo & 32,57 & 6,50 & 52,66 & 29,11 & 23,55 & 25,54 & 3,55 \\
Farináceo-duro & & & & & & & \\
BRS 1001 & 24,49 & 6,29 & 56,00 & 30,75 & 25,25 & 27,10 & 4,01 \\
Pastoso & 27,80 & 6,85 & 53,59 & 29,84 & 23,75 & 25,72 & 4,14 \\
Farináceo & 32,62 & 5,85 & 54,16 & 27,62 & 26,54 & 23,99 & 3,70 \\
Farináceo-duro & & & & & & & \\
\hline
\end{tabular}

Os inóculos foram obtidos de três vacas mestiças (Holandês x Zebu), fistuladas no rúmen, de peso aproximado de 550kg. Os animais foram alimentados com silagem de milho e $2 \mathrm{~kg}$ de concentrado comercial $(20 \%$ de proteína bruta) por dia. O líquido ruminal coletado foi retirado manualmente de várias partes do rúmen e armazenado em garrafas térmicas previamente aquecidas. No laboratório, o inóculo foi filtrado, passando por duas camadas de panos de algodão sob injeção contínua de $\mathrm{CO}_{2}$ e mantido em banho-maria a $39^{\circ} \mathrm{C}$. Os inóculos foram injetados nos frascos $(3,0 \mathrm{~mL})$ e então levados à estufa a $39^{\circ} \mathrm{C}$ até a primeira leitura.

A produção de gases foi mensurada nos tempos de $2,4,6,8,10,12,14,17,20,24,28,34,48,72$ e 96 horas após a incubação. A pressão originada pelos gases acumulados nos frascos foi medida por meio de transdutor de pressão GE-DPI 705, e a conversão dos valores da pressão dos gases para volume de gases foi estimada a partir da equação $V G=-0,0171 x^{2}+3,0926 x+0,0078$, em que $\mathrm{VG}=$ volume de gases $(\mathrm{mL}) ; \mathrm{X}=$ pressão dos gases (libra por polegada quadrada "psi - Pound square inch").

A cinética da produção cumulativa de gases foi analisada empregando-se o modelo matemático unicompartimental de France et al. (1993): Y =
A $x\left\{1-\exp ^{[-b *(t-L)-c \times(\sqrt{ } t-\sqrt{ } L)]}\right.$, em que $Y=$ produção acumulativa de gases $(\mathrm{ml}) ; \mathrm{A}=$ máxima produção acumulada de gases $(\mathrm{ml}) ; \mathrm{L}=$ é o tempo de colonização $(\mathrm{h}) ; \mathrm{b}\left(\mathrm{h}^{-1}\right)$ e $\mathrm{c}\left(\mathrm{h}^{-0,5}\right)=$ taxas fracionais constantes; $\mathrm{t}=$ tempo $(\mathrm{h})$. A taxa fracional média $\left(h^{-1}\right)$ de produção de gases $(\mu)$ foi calculada como: $\mu=b+c / 2 \sqrt{t}$, em que $\mu=$ taxa de produção de gases $\left(\mathrm{h}^{-1}\right)$. Foram ainda calculadas as degradabilidades efetivas da matéria seca para as taxas de passagem de $2 \%$ e $5,0 \% / \mathrm{h}$, empregando-se o procedimento proposto por France et al. (1993).

O delineamento experimental utilizado foi o de blocos ao acaso em esquema de parcelas subdivididas. Foram utilizados três blocos (inóculos). As idades de corte, os híbridos e suas interações foram alocados na parcela inteira, e os tempos de incubação, nas subparcelas. As médias foram comparadas utilizando-se o teste SNK $(\mathrm{P}<0,05)$.

\section{RESULTADOS E DISCUSSÃO}

Ao longo do processo fermentativo, de 6 até 96 horas de incubação, houve aumento na produção cumulativa de gases (PCG). Após 24 e 48 horas de fermentação, não houve diferença na PCG para as silagens do híbrido BRS 1035 cortado nos diferentes estádios de maturidade $(\mathrm{P}>0,05)$. 
Já para as silagens do híbrido BRS 1031, após 24 e 48 horas de fermentação, a silagem cortada no ponto farináceo apresentou maior PCG em relação à silagem colhida no estádio farináceoduro $(\mathrm{P}<0,05)$; já a silagem colhida no estádio pastoso não diferiu das anteriores $(\mathrm{P}>0,05)$. Para as silagens do híbrido BRS 1001, após 24 horas de incubação, o material colhido no estádio farináceo-duro apresentou maior PCG, enquanto a silagem colhida no estádio pastoso apresentou menor PCG $(\mathrm{P}<0,05)$. Com 48 horas de fermentação, a silagem do híbrido BRS 1001 obtida no ponto farináceo-duro apresentou maior PCG em relação às silagens colhidas nos demais estádios $(\mathrm{P}<0,05)$.

Para as silagens do híbrido BRS 1031 colhidas em três idades, com 24 horas de incubação, a silagem colhida no estádio farináceo apresentou maior PCG em relação à colhida no estádio farináceo-duro, sendo que a silagem colhida no estádio pastoso não diferiu das demais. O mesmo comportamento foi observado quando o tempo de fermentação atingiu 48 horas. Já com 96 horas de fermentação, as silagens obtidas nos diferentes estádios apresentaram valores semelhantes $(\mathrm{P}>0,05)$ para as PCG. $\mathrm{Na}$ estequiometria da fermentação das hexoses no rúmen (Wolin, 1983), as reações de produção de propionato não formam $\mathrm{CO}_{2}$, o que reduz o potencial de produção de gases. Quando a fermentação das hexoses é favorável à formação de acetato e butirato, há produção de $\mathrm{CO}_{2}$, aumentando assim o potencial máximo de produção de gases. A maior proporção de acetato ocorre a partir da fermentação das frações fibrosas. Como se pode observar na Tabela 1, não houve variação nos valores de FDN das silagens do híbrido BRS 1031 com o avanço dos estádios de maturidade da planta. Dessa forma, essa diferença de PCG que se deu nos tempos de incubação de 24 e 48 horas pode ter ocorrido devido à maior quantidade de amido nos grãos com o avançar da maturidade, favorecendo assim a produção de propionato na fermentação ruminal, reduzindo a PCG.

Tabela 2. Produção acumulativa de gases (mL/g de MS) pela técnica in vitro semiautomática de produção de gases das silagens de três híbridos de milho colhidos em três idades

\begin{tabular}{lccccc}
\hline \multirow{2}{*}{ Híbridos } & \multicolumn{5}{c}{ Tempo de Fermentação } \\
\cline { 2 - 6 } \multicolumn{1}{c}{ BRS 1035 } & 6 & 12 & 24 & 48 & 96 \\
Pastoso & 58,95 & 96,61 & 142,41 & 208,95 & 254,18 \\
Farináceo & 55,53 & 96,41 & 163,76 & 229,25 & 276,52 \\
Farináceo-duro & 44,08 & 86,56 & $163,91 \mathrm{~B}$ & $226,94 \mathrm{~B}$ & 265,53 \\
\hline \multicolumn{1}{c}{ BRS 1031 } & & & & \\
Pastoso & 57,34 & 101,64 & $159,91 \mathrm{ab}$ & $228,10 \mathrm{ab}$ & 272,01 \\
Farináceo & 53,26 & 99,23 & $176,80 \mathrm{a}$ & $243,01 \mathrm{a}$ & 282,05 \\
Farináceo-duro & 43,64 & 80,67 & $144,84 \mathrm{bB}$ & $213,03 \mathrm{bB}$ & 263,35 \\
\hline \multicolumn{1}{c}{ BRS 1001 } & & & & \\
Pastoso & 57,51 & 98,91 & $155,64 \mathrm{c}$ & $222,49 \mathrm{~b}$ & 265,69 \\
Farináceo & 52,06 & 98,66 & $172,10 \mathrm{~b}$ & $233,83 \mathrm{~b}$ & 268,02 \\
Farináceo-duro & 45,89 & 97,53 & $191,29 \mathrm{aA}$ & $250,12 \mathrm{aA}$ & 276,69 \\
\hline
\end{tabular}

Médias seguidas por letras maiúsculas diferentes na mesma coluna apresentam diferença entre os pontos de colheita dos diferentes híbridos pelo teste SNK $(\mathrm{P}<0,05)$. Letras minúsculas na mesma coluna se diferem entre os cortes de um mesmo híbrido. $\mathrm{CV}=6,87 \%$.

Para as silagens do híbrido BRS 1001, pode-se observar que, com 24 horas de fermentação, a PCG foi maior para a silagem colhida no estádio farináceo-duro. A silagem colhida no estádio farináceo apresentou maior PCG em relação à colhida no estádio pastoso. Com 48 horas de fermentação, a PCG foi maior para a silagem produzida no estádio farináceo-duro, sendo que a PCG da silagem obtida no estádio pastoso foi semelhante $(\mathrm{P}>0,05)$ à do ponto farináceo.
Quando o período de incubação atingiu 96 horas, as silagens obtidas nos três estádios de crescimento apresentaram PCG semelhantes (P>0,05). Segundo Corrêa et al. (2002), com o avançar da maturidade da planta de milho, ocorre um aumento na vitreosidade e na densidade dos grãos, e, consequentemente, redução na degradabilidade do amido, o que pode ter levado a uma redução na quantidade de substrato 
disponível para a fermentação ruminal e produção de propionato.

A maior PCG encontrada para a silagem do híbrido BRS 1001 colhida no ponto farináceoduro, nos tempos de fermentação de 24 e 48 horas, pode ser explicada por uma menor disponibilidade do amido nos grãos com o avançar da maturidade da planta. Já para as silagens do híbrido BRS 1031, o aumento da vitreosidade dos grãos com o avanço da maturidade da planta pode ter sido suficiente para provocar redução na digestibilidade do amido. Os grãos do híbrido BRS 1001 são classificados como duros, enquanto os do híbrido BRS 1031 são semiduros. Nesse sentido, segundo Pereira et al. (2004), o aumento da vitreosidade por dia de maturação da planta é maior nos híbridos duros do que nos dentados, de forma que nos dentados pode ocorrer menor queda relativa na fermentação ruminal do amido com o avançar da maturidade.

Para as silagens colhidas no estádio farináceoduro, nos tempos de incubação de 24 e 48 horas, houve maior PCG para as silagens do híbrido BRS 1001. Para os demais tempos de fermentação, não houve diferença entre as silagens dos híbridos $(\mathrm{P}>0,05)$. Essa maior PCG para o híbrido BRS 1001, às 24 e 48 horas de fermentação, pode ter ocorrido devido à maior vitreosidade dos grãos (duros) em relação aos demais.

Faria et al. (2008), também avaliando silagem de milho, encontraram valores de PCG semelhantes aos do presente estudo, sendo 48,99; 112,13; 174,40 e $249,58 \mathrm{~mL} / \mathrm{g}$ de MS para os tempos 6 , 12, 24 e 96 horas, respectivamente.

Para as silagens dos três híbridos avaliados, o potencial máximo de produção de gases $(A)$ foi maior para as silagens colhidas no estádio pastoso, ocorrendo redução desse parâmetro com o avançar da maturidade da planta (Tab. 3). Houve variação de 259,32 a 279,96mL/g de MS para o $A$, valores superiores aos reportados por Ribas (2007), que observou variação de 219 a $233 \mathrm{~mL} / \mathrm{g}$ de MS para as silagens dos quatro híbridos de milho avaliados. Com o avançar da idade, houve redução no potencial máximo de produção de gases. Porém, a avaliação do potencial máximo de produção de gases deve ser criteriosa, pois a relação entre os ácidos graxos voláteis no produto final da fermentação, principalmente acetato/propionato, tem efeito direto sobre esse parâmetro (Getachew et al., 1998). Dessa forma, com o avançar da maturidade da planta de milho, ocorre maior acúmulo de amido nos grãos, favorecendo maior produção de propionato no rúmen, reduzindo assim o potencial máximo de produção de gases.

Para as silagens dos híbridos BRS 1035 e BRS 1001, houve aumento no tempo de colonização (lag) com o aumento da idade da planta. Para as silagens do híbrido BRS 1031, houve aumento no lag quando a planta passou do estádio pastoso para farináceo, e uma redução quando avançou para farináceo-duro. Esse aumento no lag em relação à idade da planta pode ter ocorrido devido à lignificação da fração fibrosa com o avançar da idade. Com o avanço da maturidade fisiológica da planta, a proporção de espigas também aumenta, porém a vitreosidade dos grãos também se eleva, dificultando o acesso da microbiota aos grânulos de amido. As silagens do híbrido BRS 1001 apresentam grãos duros, enquanto os demais híbridos são semiduros, justificando o maior valor de lag para as silagens desse híbrido no estádio farináceo-duro. Quanto maior o tempo de maturidade da planta, maior a vitreosidade dos grãos, principalmente nos grãos duros (Pereira et al., 1994).

Com o avançar da maturidade fisiológica, as silagens dos híbridos BRS 1035 e BRS 1001 apresentaram aumento gradativo da taxa fracional de produção de gases $(\mu)$. Já para as silagens do híbrido BRS 1031, houve um aumento nos valores de $\mu$ entre os estádios pastoso e farináceo, e uma redução quando avançou para farináceo-duro. Houve uma variação na $\mu$ de $0,0292 \mathrm{~mL} / g$ de $\mathrm{MS} / \mathrm{h}$ a $0,0447 \mathrm{~mL} / \mathrm{g}$ de $\mathrm{MS} / \mathrm{h}$.

Os valores de degradabilidade efetiva da matéria seca nas diferentes taxas de passagem $(2,0$ e $5,0 \%$ /hora) foram superiores para as silagens obtidas no estádio pastoso para as silagens de todos os híbridos avaliados. A degradabilidade efetiva foi se reduzindo com o avançar da maturidade da planta, provavelmente devido ao aumento da vitreosidade dos grãos, que pode reduzir a digestibilidade do amido. 
Tabela 3. Potencial máximo de produção de gases (A) em $\mathrm{mL} / \mathrm{g}$ de MS, tempo de colonização em horas e minutos (Lag), taxa de produção de gases $(\mu) \mathrm{em} \mathrm{mL} / \mathrm{g}$ de $\mathrm{MS} / \mathrm{h}$, degradabilidade efetiva da matéria seca (DE) $(\% / h)$ das silagens de três híbridos de milho cortados em três épocas

\begin{tabular}{|c|c|c|c|c|c|c|c|}
\hline \multirow{2}{*}{ Híbridos } & \multirow[b]{2}{*}{ A } & \multirow[b]{2}{*}{ Lag } & \multirow[b]{2}{*}{$\mu$} & \multirow[b]{2}{*}{$\mathrm{R}^{2}$} & \multicolumn{2}{|c|}{$\mathrm{DE}(\%)$} & \multirow[b]{2}{*}{ Equações } \\
\hline & & & & & 2,0 & 5,0 & \\
\hline \multicolumn{8}{|l|}{ BRS 1035} \\
\hline Farináceo & 272,25 & $0: 27$ & 0,0361 & 0,98 & 69,01 & 66,09 & 2 \\
\hline Farináceo-duro & 259,32 & $1: 20$ & 0,0447 & 0,97 & 67,04 & 62,56 & 3 \\
\hline \multicolumn{8}{|l|}{ BRS 1031} \\
\hline Farináceo & 273,09 & $1: 08$ & 0,0426 & 0,97 & 71,56 & 67,45 & 5 \\
\hline Farináceo-duro & 261,02 & $0: 54$ & 0,0346 & 0,95 & 67,57 & 63,85 & 6 \\
\hline \multicolumn{8}{|l|}{ BRS 1001} \\
\hline Pastoso & 275,65 & $0: 06$ & 0,0337 & 0,98 & 74,45 & 72,02 & 7 \\
\hline Farináceo & 261,27 & $0: 51$ & 0,0441 & 0,97 & 72,30 & 68,44 & 8 \\
\hline
\end{tabular}

A DMS com 96 horas de fermentação variou de 70,14 a 76,40\% (Tab. 4). Para as silagens do híbrido BRS 1035 colhidas nos diferentes estádios de crescimento, apenas no período de fermentação de 24 horas houve diferença na DMS das silagens $(\mathrm{P}<0,05)$. A silagem colhida no estádio farináceo apresentou maior valor de DMS em relação à colhida no estádio pastoso, não havendo diferença entre a DMS da silagem colhida no estádio farináceo-duro e as demais $(\mathrm{P}>0,05)$. Em relação à $\mathrm{PCG}$, não foram observadas diferenças no tempo de incubação de 24 horas para as silagens do híbrido BRS 1035 colhidas em três épocas. A menor DMS observada para a silagem colhida no estádio pastoso pode estar relacionada a um menor acúmulo de carboidratos não fibrosos nessa fase. A DMS das silagens do híbrido BRS 1031 colhidas em três épocas apresentou um comportamento semelhante à PCG, de forma que a DMS foi menor para a silagem produzida no ponto farináceo-duro para os tempos de fermentação de 12, 24, 48 e 96 horas, sendo que, para o tempo de fermentação de 6 horas, não houve diferença na DMS entre as silagens colhidas nos três estádios de maturidade.

Tabela 4. Degradabilidade da matéria seca, em porcentagem, após 6, 12, 24, 48 e 96 horas de fermentação das silagens de três híbridos de milho colhidos em três épocas.

\begin{tabular}{lccccc}
\hline \multirow{2}{*}{ Híbridos } & \multicolumn{5}{c}{ Tempo de Fermentação } \\
\cline { 2 - 6 } \multicolumn{1}{c}{ BRS 1035 } & 6 & 12 & 24 & 48 & 96 \\
\hline Pastoso & 31,13 & 33,24 & $38,88 \mathrm{bB}$ & 59,83 & $73,08 \mathrm{~B}$ \\
Farináceo & $27,78 \mathrm{~B}$ & 32,54 & $43,76 \mathrm{a}$ & 60,84 & 71,00 \\
Farináceo-duro & $27,25 \mathrm{~B}$ & $29,64 \mathrm{~B}$ & $42,07 \mathrm{abB}$ & $56,74 \mathrm{~B}$ & $70,18 \mathrm{~B}$ \\
\hline \multicolumn{1}{c}{ BRS 1031 } & 32,63 & $34,62 \mathrm{a}$ & $43,32 \mathrm{aA}$ & $61,01 \mathrm{a}$ & $74,13 \mathrm{aAB}$ \\
Pastoso & $31,01 \mathrm{AB}$ & $32,97 \mathrm{a}$ & $45,30 \mathrm{a}$ & $62,85 \mathrm{a}$ & $74,41 \mathrm{a}$ \\
Farináceo & $25,38 \mathrm{~B}$ & $26,54 \mathrm{bB}$ & $36,64 \mathrm{bC}$ & $54,14 \mathrm{bB}$ & $70,14 \mathrm{bB}$ \\
Farináceo-duro & 33,64 & 34,51 & $43,67 \mathrm{cA}$ & 61,88 & $76,08 \mathrm{~A}$ \\
\hline \multicolumn{1}{c}{ BRS 1001 } & $32,56 \mathrm{~A}$ & 33,76 & $46,69 \mathrm{~b}$ & 64,54 & 74,97 \\
Pastoso & $34,78 \mathrm{~A}$ & $34,75 \mathrm{~A}$ & $50,85 \mathrm{aA}$ & $65,30 \mathrm{~A}$ & $76,40 \mathrm{~A}$ \\
Farináceo &
\end{tabular}

Letras minúsculas na mesma coluna diferem entre os cortes do híbrido avaliado pelo teste $\mathrm{SNK}(\mathrm{P}<0,05)$. Médias seguidas pelas letras maiúsculas diferem as silagens dos diferentes híbridos colhidos no mesmo corte pelo teste SNK $(\mathrm{P}<0,05) . \mathrm{CV}=3,89 \%$. 
Em relação às silagens do híbrido BRS 1001 obtidas em três épocas, apenas no período de incubação de 24 horas houve diferença na DMS. A silagem produzida no estádio farináceo-duro apresentou maior DMS $(50,85 \%)$, enquanto a silagem colhida no estádio pastoso apresentou o menor valor de DMS (43,67\%). A maior DMS observada com o avançar do estádio de maturação no tempo de fermentação de 24 horas pode ter ocorrido devido a um maior acúmulo de amido.

Comparando-se a DMS das silagens dos diferentes híbridos colhidos no mesmo estádio de maturidade, para as silagens colhidas no estádio pastoso, houve diferença na DMS das silagens para os tempos de 24 e 96 horas. Após 24 horas de fermentação, a silagem do híbrido BRS 1035 apresentou menor DMS em relação às silagens dos demais híbridos $(\mathrm{P}<0,05)$. Para o tempo de incubação de 96 horas, a silagem do híbrido BRS 1001 apresentou maior DMS em relação à silagem do híbrido BRS 1035, de forma que a silagem do híbrido BRS 1031 não diferiu das anteriores $(\mathrm{P}>0,05)$. Em relação às silagens colhidas no estádio farináceo, houve diferença na DMS das silagens dos híbridos apenas no tempo de fermentação de 6 horas, sendo que a silagem do híbrido BRS 1001 apresentou maior DMS em relação à silagem do híbrido BRS $1035(\mathrm{P}<0,05)$, não havendo diferença na DMS da silagem do híbrido BRS 1031 ( $\mathrm{P}>0,05)$. Em relação às silagens colhidas no estádio farináceo-duro, houve diferença na DMS em todos os tempos de fermentação avaliados. A silagem do híbrido BRS 1001 apresentou maior DMS em relação às demais $(\mathrm{P}<0,05)$ nos tempos de incubação de 6 , 12,48 e 96 horas. No tempo de incubação de 24 horas, a silagem do híbrido BRS 1001 apresentou maior DMS, enquanto a silagem do híbrido BRS 1035 apresentou o menor valor.

\section{CONCLUSÕES}

A silagem do híbrido BRS 1035 apresentou melhor valor nutricional quando colhida no estádio pastoso. Já a silagem do híbrido BRS 1031 apresentou valor nutricional superior no estádio farináceo, enquanto a silagem do híbrido BRS 1001 apresentou melhor valor nutricional no estádio farináceo-duro.

\section{REFERÊNCIAS}

BELVINK, J.M.W.; SPOELSTRA, S.F. Interaction betweem substrate, fermentation end-products, buffering systems and gas production upon fermentation of different carbohydrates by mixed rumen microorganisms in vitro. Appl. Microb. Biotech., v.37, p.505-509, 1992.

CORRÊA, C.E.S.; SHAVER, R.D.; PEREIRA, M.N. et al. Relationship between corn vitrousness and ruminal in situ starch degradability. J. Dairy Sci., v.85, p.3008-3012. 2002 .

FARIA, B.N.; REIS, R.B.; MAURÍCIO, et al. Efeitos da adição de propilenoglicol ou monensina à silagem de milho sobre a cinética de degradação dos carboidratos e produção cumulativa de gases in vitro. Arq. Bras. Med. Vet. Zootec., v.60, p.177-182, 2008.

FRANCE, J.; DHANOA, M.S.; THEODOROU, M.K. et al. A model to interpret gas accumulation profiles associated with in vitro degradation of ruminant feeds. J. Theo. Bio, v.163, p.99-111, 1993.

GETACHEW, G.; BLÜMMEL, M.; MAKKAR, H.P.S. et al. In vitro gas measuring techniques for assesment of nutritional quality of feeds: a review. Anim. Feed Sci. Techn., v.72, p.261-281, 1998.

MAURÍCIO, R.M.; PEREIRA, L.G.R.; GONCALVES, L.C. et al. Relação entre pressão e volume para implantação da técnica in vitro semiautomática de produção de gases na avaliação de forrageiras tropicais. Arq. Bras. Med. Vet. Zootec., v.55, p.216-219, 2003.

MENKE, B.K.H.; RAAB, L.; SALEWSKI, A. The estimation of the digestibility and metabolizable energy content of ruminant feeding stuffs from the gas production when they are incubated with rumen liquor in vitro. J. Agric. Sci, v.93, p.217-223. 1979.

PEREIRA, M.N.; VON PINHO, R.G.; BRUNO, R.G.S.; CELESTINE, G.A. Ruminal degradability of hard or soft texture corn grain at three maturity stages. Sci. Agric., v.61, p.358-363, 2004.

RIBAS, M.N.; GONÇALVES, L.C.; MAURÍCIO, R.M. Degradabilidade e cinética de fermentação ruminal das silagens de quatro híbridos de milho, avaliadas pela técnica in vitro semi-automática de produção de gases. Ver. Bras. Mil. Sor., v.6, p.223233, 2007

WOLIN, M.J. A theorical rumen fermentation balance. J. Anim. Sci., v.43, p.1452-1459, 1983. 